\title{
Qualidade total e administração hospitalar: explorando disjunções conceituais
}

Total quality management and hospital administration: exploring conceptual disjunctions

Garibaldi Dantas Gurgel Júnior 1

M arcelo M ilano Falcão Vieira 2

\footnotetext{
1 Núcleo de Estudos em Saúde Coletiva do Centro de Pesquisa Aggeu Magalhães, Fiocruz. Rua José Carvalheira 35/701, Tamarineira, 52051-060, Recife PE. gurgel@cpqam.fiocruz.br 2 Escola de Administração Pública e de Empresas da Fundação Getúlio Vargas do Rio de Janeiro.

Programa de Pós-graduação em Administração das Universidades Federais de Pernambuco e Rio Grande do Sul.
}

\begin{abstract}
In this paper we discuss total quality management (TQM) and its applicability to hospital administration. We approach the subject by its historical context pointing out to the consequences of TQM implementation in organizations. A number of factors involving the process of TQM implementation are discussed for their potential to lead organizations to success or failure. Such a discussion allows the development of a critical point of view on the subject aiming at enhancing managerial aspects of hospital administration.
\end{abstract}

Key words Hospital administration, Total quality management, Accreditation of health organizations
Resumo Neste artigo discute-se o gerenciamento da qualidade total e sua aplicabilidade na administração hospitalar, abordando o movimento da qualidade no contexto histórico e as conseqüências da implementação destes programas para as organizações. Identificam-se, com base nas características historico-estruturais das organizações hospitalares e dos conceitos e técnicas dos programas de qualidade total, elementos que podem contribuir para seu sucesso ou fracasso, como forma de desenvolver uma visão crítica e delimitar melhor o alcance dos programas no incremento gerencial destas organizações.

Palavras-chave Administração hospitalar, Qualidade total, Acreditação hospitalar 


\section{A qualidade nos serviços de saúde}

O bserva-se nas últimas décadas, em vários países, uma mobilização em torno da aplicação de programas de qualidade nas organizações hospitalares, com o objetivo de incrementar seu gerenciamento e melhorar a eficiência destes serviços (Camacho, 1998). Dentro deste contexto, desenvolve se no Brasil, já há al guns anos, instrumentos oficiais de avaliação da performance das organizações hospitalares do SistemaÚ nico de Saúde, utilizando-se um conjunto de critérios que os hospitais devem preencher, a partir de padrões preestabelecidos, tendo por base a aplicação de conceitos e técnicas da qualidade total (Quinto N eto, 2000). Fenômeno semel hante pode ser observado nos hospitais da rede privada suplementar, que fazem uso de certificações proferidas por organizações avaliadoras de reconhecimento internacional como diferencial de mercado, demonstrando uma crescente preocupação com a qualidade.

Atualmente, a adoção dos programas de qualidade no setor saúde está fortemente relacionada ao crescimento dos custos da assistência hospitalar, quando comparados ao gasto total em saúde. Nos últimos anos a agenda mundial de reforma do setor saúde adota um conjunto de ações com o objetivo de reduzir os custos da assistência à saúde dentro de uma política de atenção administrada. N este sentido, os governos de vários países estimularam, dentre outras medidas, a concorrência entre os hospitais; passaram a limitar o pagamento total das faturas, a encorajar um melhor gerenciamento das organizações de saúde através de programas de qualidade, a limitar procedimentos e acesso a subgrupos populacionais mais susceptíveis, e, por fim, a desviar alguns custos para os usuários (Costa, 1996).

Entretanto, existem nas organizações hospitalares algumas especificidades de natureza econômica (Campos, 1998) e organizacional (Foucault, 1981; Azevedo, 1993; Nogueira, 1994; M intzberg, 1995) que podem se colocar como possíveis obstáculos à introdução de programas de qualidade. É sobre estas questões que este artigo procura se aprofundar, pontuando inicial mente al gumas dessas características para demonstrar as dificuldades na implementação destes programas nas organizações prestadoras de assistência à saúde:

a) as leis de mercado não se aplicam bem ao setor em face das necessidades humanas e prioridades não-mercantis, que se impõem inde- pendentemente dos custos de produção, valor de mercado e preços praticados;

b) a concorrência não é um elemento forte no ambiente destas organizações, pois este é um segmento cronicamente carente em alguns países;

c) a variabilidade da assistência demandada é enorme e cada paciente se comporta subjetivamente de maneira diferente, o que dificulta uma rígida padronização do processo de trabaIho em saúde e a racionalização da oferta de serviços;

d) não há simetria de informação neste mercado, pois os clientes são geral mente leigos e não têm capacidade de julgar seu tratamento, nem suas necessidades, o que dificulta o exercício das suas opções de consumo;

e) o consumo do serviço é imediato à produção e, portanto, não há tempo para o controle prévio da qualidade, nem estoque para inspeção final;

g) a produção do serviço é executada por uma grande variedade de profissionais de diversos níveis de escolaridade e formação, com interesses corporativos distintos;

h) a categoria médica apresenta forte resistência aos programas por sentir-se fiscalizada e tolhida na conduta clínica dos pacientes ante 0 controle externo;

Por outro lado, há fortes argumentos utilizados para a adoção de programas de qualidade total na administração hospitalar, pois não é suficiente reunir o melhor corpo clínico para que a organização preste assistência de qualidade, já que esta depende de um conjunto de outros fatores comuns às organizações de vários setores (N ogueira 1999).

Segundo Berwick (1994), a intervenção dos programas não se faz diretamente sobre 0 ato clínico, mas é fundamental nos processos administrativos da organização hospitalar e a gestão profissionalizada, para que se alcance a qualidade nestes serviços. Os setores administrativos (faturamento, contas médicas, al moxarifado), os serviços de apoio logístico (lavanderia, transporte), enfim, todas as áreas da organização que garantem o funcionamento dos setores operacionais e se comportam como "amortecedores" seriam os objetos destes programas. Eles impedem que os setores operacionais finalistícos desperdicem seu tempo na resolução de problemas administrativos, que não é seu foco de trabal ho, e se concentrem nas suas funções com melhores resultados. Além disso, argumenta-se ainda que o instrumental estatístico 
desenvolvido pelos autores da qualidade, aliado ao instrumental da epidemiologia de serviços de saúde, utilizada na rotina da administração hospitalar, se constitui numa importante ferramenta de gestão, podendo contribuir significativamente para melhoria da qualidade da assistência (Donabedian apud Malik, 1998).

De acordo com Berwick (1994), o Programa de Demonstração Nacional de M elhoria da Qualidade de Serviços de Saúde, experiência realizada nos EUA, surpreendeu pela adesão e pelos resultados al cançados em termos de treinamento de pessoal, na busca da satisfação da clientela, que passou a ser ouvida com base em pesquisas de opinião realizadas; na capacitação gerencial para definir e resolver problemas; no alcance de metas estabelecidas; e, sobretudo, pela possibilidade de ser um caminho viável para mudança intra-organizacional necessária ao setor. Para seus responsáveis, os princípios básicos da qualidade total poderiam ser aplicados com êxito na administração hospitalar, mesmo considerando-se suas especificidades.

No Brasil gasta-se, historicamente, pouco mais de 80 dólares per capita com saúde anualmente e com desperdício significativo de recursos ( M edici, 1995). Este fato, aliado à crise de gestão do setor saúde no Brasil, que se expressa pela precariedade da assistência hospitalar ( M ezomo, 1994), tem justificado o esforço para implantação de programas de qualidade, com 0 objetivo de atender ao apelo da promoção da melhoria dos serviços prestados e redução de desperdícios. Assim, trabal ham em conjunto instituições públicas e privadas para a elaboração de instrumentos de avaliação a partir da experiência acumulada em outros países (Schiesari, 1999) . A institucionalização do processo de acreditação hospitalar no Brasil com a aplicação sistemática dos manuais de acreditação é a expressão concreta deste esforço. N este sentido, a evolução e adequação destes programas ao setor saúde apontam para o mesmo processo histórico vivenciado em outros setores já há alguns anos, como passamos a observar.

\section{0 movimento da qualidade ao longo da história}

A qualidade como objeto de atenção gerencial pode ser identificada desde os primórdios da atividade manufatureira, ainda no período em que predominava a produção em caráter artesanal. A observação por parte dos mestres-ar- tesãos aos aprendizes era o principal instrumento de controle da qualidade, cujo objetivo era evitar falhas no processo de manufatura.

No início do século 20, com a evolução das organizações manufatureiras para indústria ea produção em larga escala, houve enormes mudanças nos processos de trabalho, e el evação da produtividade, a partir da aplicação dos estudos de Henry Ford, que culminaram na clássica divisão do trabalho em tempos e movimentos. 0 uso intenso de máquinas para auxiliar a produção em massa e a forte preocupação com a uniformidade dos produtos deram origem à atividade de inspeção, posteriormente organizada sob forma de departamento no interior das fábricas. Sua responsabilidade consistia em inspecionar o produto final e separar os defeituosos, para evitar que sua comercialização comprometesse o nome da empresa no mercado.

Pode-se caracterizar este período como a primeira fase do movimento da qualidade e o início da atividade voltada para este objetivo de forma científica e sistematizada, utilizando-se para isso, medidas e gabaritos com modelos padrão (Garvin, 1992). Esta forma de trabalho foi desenvolvida, sobretudo, na indústria bélica. A administração científica introduzida por Taylor e a criação de postos de inspetores de fábrica consolidam esta etapa nos anos 20 do século passado.

A evolução da atividade de inspeção trouxe no seu bojo a formação de Departamentos de Engenharia de Produção que se utilizam do instrumental estatístico voltado para a medição e o controle da qualidade. 0 controle de qualidade do produto final foi a etapa seguinte neste processo, cujo caráter científico foi dado por W. Shewhart, através da obra Economic control of quality of manufactured product, publicado em 1931 (Garvin, 1992). Este autor era responsável pelo grupo de pesquisas da Bell Telefhones Laboratories, envolvido com a qualidade dos novos e complexos sistemas de comunicação que estavam sendo implantados nos Estados Unidos.

Na concepção deste grupo de pesquisa era impossível que duas peças fossem exatamente iguais, pois existiria um certo grau de variabilidade inerente ao produto, em função de matéria-prima, da máquina ou do operador, fato que determinou uma nova postura diante dos problemas de variação da produção. A atenção passou a ser dada ao grau de variação suportável, que não levasse efetivamente a problemas. Essas idéias deram origem ao controle estatísti- 
co por amostragem, com a criação de técnicas de limites de variação aceitável durante todo o processo fabril e não apenas no final da produção.

A influência da Segunda Guerra Mundial elevou a exigência de qualidade e confiabilidade nos armamentos e a necessidade de volume maior de produtos. Este fato teve como conseqüência direta a diminuição do tempo disponível para a inspeção final. Dessa forma, o uso do controle estatístico do processo por amostragem passou a predominar, permitindo ganho de produtividade e qualidade na indústria. Nos anos 40, o controle de qualidade estava consolidado como uma disciplina acadêmica nos cursos de engenharia, o que estabeleceu uma nova etapa do processo.

Nos anos 50 e 60 houve uma grande evolução no gerenciamento das empresas, sobretudo, no Japão, motivadas pela necessidade de reconstrução da economia nipônica após a Segunda Grande Guerra. N essa época, desenvolveram-se quatro elementos básicos no processo de evolução da qualidade: a Quantificação dos Custos da Qualidade, o Controle Total da Qualidade, a Engenharia da Confiabilidade e 0 Programa de Zero D efeito. Inicia-se, assim, a Era da Garantia da Qualidade, cujo objetivo era prevenir os problemas, porém usando mais do que técnicas estatísticas para esta finalidade. Dessa forma, E. Deming, J. M . Juran e Armand Feigenbaun empreenderam grandes esforços no exercício de práticas gerenciais voltadas para a qualidade nas organizações japonesas, fundamentadas em teorias desenvolvidas nas décadas anteriores (Wood, 1994). N esse período foram sistematizadas abordagens para solução de problemas organizacionais tornando-se conhecidas como o PDCA (Plan, Do, Check, Action) ou Ciclo de Deming.

A Quantificação dos Custos da Qualidade foi primeiramente apresentada em 1951, por J. Juran, em seu livro Q uality control handbook. Ele abordava a questão dos custos da não-qualidade, enfatizando o quanto a organização perdia em função de defeitos na produção, representada pelo sobretrabalho e retrabalho, e na insatisfação dos clientes com os produtos de baixa qualidade. Juran considerava que os custos evitáveis eram o mapa da mina das empresas, pois poderiam impedir prejuízos financeirose melhorar a competitividade da empresa no mercado (Garvin, 1992).

Em 1956, Armand Feigenbaum propôs um conceito mais avançado, o Controle Total da Qualidade, partindo da premissa que a quali- dade do produto é objeto de todos na organização, desde a concepção, passando pela fabricação, até a chegada dos produtos às mãos dos clientes. Portanto, na sua visão a qualidade não é um trabalho isolado do Departamento de Controle, é na verdade objetivo de toda organização, da alta gerência aos setores operacionais. A qualidade passou a ser então uma questão de sobrevivência no mercado concorrencial e um objetivo de níveis gerenciais mais el evados, a partir do início da cadeia produtiva, perpassando desde a concepção do projeto da organização até seus produtos.

A partir desse conceito, foram criadas as equipes interfuncionais, com o objetivo de discutir os processos de padronização dos produtos, que se iniciavam na formulação do projeto, na escolha de bons fornecedores, no controle da produção e na satisfação dos clientes, inclusive no período da pós-venda, mantendo-se o controle estatístico por amostragem, mas não se limitando a ele.

Um outro componente importante desenvolvido, pelos mesmos autores, com forte crença na probabilidade e na estatística foi a Engenharia de Confiabilidade, cujo objetivo era garantir a durabilidade e a funcionalidade dos produtos ao longo do tempo. Estas idéias tiveram forte influência da indústria aeroespacial que permitiu expandir a garantia dos produtos tornando-se um importante diferencial competitivo.

A outra idéia desenvolvida nesse período, 0 Programa de Zero Defeito, tinha como objetivo realizar, de uma só vez, a fabricação de um produto sem defeitos, evitando-se a necessidade de refazêlo. Este conceito exi gia muita atenção no processo fabril e motivação dos que estavam envolvidos na sua realização. Este quarto e último componente da era da Garantia da Qualidade determinou novos rumos ao movimento, quando se passou a considerar aspectos comportamentais no gerenciamento das organizações, pois o instrumental desenvolvido até então não prevenia, nem resolvia os problemas que originavam a má qualidade, não encontrava os obstáculos ao fluxo de trabalho - o retrabalho e o sobretrabalho - e nem suas repercussões na performance da empresa. Era, portanto, um processo ainda ineficiente e ineficaz.

Posteriormente, a preocupação com os custos de produção e a incorporação do conceito da satisfação do cliente representaram um substancial avanço. 0 acirramento do mercado concorrencial, com clientes cada vez mais exigen- 
tes, amparados pela criação de leis e códigos de defesa do consumidor, e, sobretudo, a necessidade de as empresas produzirem mais e melhor com custos menores ao mesmo tempo deram uma nova amplitude aos programas de qualidade. Com o aumento da competitividade e 0 nivelamento tecnológico, a busca da qualidade passou a ser um diferencial importante para as empresas.

A aplicação dos programas de qualidade deu origem às certificações ISO, que incorporam rigorosos parâmetros de avaliação da performance organizacional e vinculam, de acordo com a classificação da organização avaliada, a possibilidade de auferir maior volume de re cursos e expansão de mercado.

$\mathrm{Na}$ sua abordagem gerencial contemporânea, a Gestão Estratégica da Q ualidade envolve o uso de técnicas comportamentais, a utilização do conceito de clientes internos e externos, cuja satisfação é o objetivo maior, a quebra da dicotomia entre o fazer e o pensar típico da administração taylorista, a formação de equipes que pensam e executam os projetos, e a ênfase nos processos e fluxos de trabal ho, a partir da estruturação organizacional adequada.

A qualidade passou a ser um objetivo perseguido pela cúpula estratégica das organizações, tornando-se objeto de interesse das grandes corporações nos dias atuais, tanto no setor fabril como no setor de serviços. Apesar de divergências, o prêmio Baldrige é considerado o Nobel da qualidade das empresas, que concorrem anualmente, havendo uma forte correlação entre as que alcançam os primeiros lugares e uma posição favorável no mercado (Wisner \& Eakins,1997).

$\mathrm{Na}$ atualidade, a qualidade é encarada como um conjunto de atributos essenciais à sobrevivência das organizações num mercado altamente competitivo, objeto da gerência estratégica, líder do processo, que envolve planejamento estratégico, estabelecimento de objetivos e mobilização de toda organização. É o clímax de uma tendência que teve início no começo do século 20 (Garvin, 1992), e que envolve, também na atualidade, a responsabilidade social das empresas com o seu ambiente externo, potencializando seu uso em vários setores da economia e mais notadamente no setor de serviços.

\section{A organização hospitalar e suas singularidades}

O hospital com as características observadas nos dias atuais éalgo muito recente. Uma organização como instrumento de interven ção terapêutica com o objetivo de alcançar a cura de doentes é uma invenção relativamente nova. Segundo Foucault (1981), os primeiros hospitais datam do final do século 18. É nesse período que a Academia de Ciências da França busca uma padronização para os hospitais existentes, a partir de uma série de viagens de pesquisa, cujo objetivo era estudar aspectos físicos e funcionais para transformar os depósitos de doentes da época em instituições que buscassem a assistência à saúde, um local de prática médica. Antes do século 18, os hospitais serviam para separar os enfermos da sociedade, para esperar a morte, não havendo quase nenhuma intervenção sobre a doença ou o doente.

A formação médica, que não incluía atividade hospitalar, passou, após essa fase, a ser uma atividade rotineira, com visita e evolução hospital ar dos pacientes realizadas por médicos, cujo trabalho era observar o comportamento dos doentes e tentar auxiliar a natureza no processo de cura.

As guerras levaram à necessidade da criação de hospitais militares, abundantes na Europa em séculos passados. Sua disciplina foi incorporada por estas instituições e influenciou o funcionamento hospitalar tal como conhecemos hoje, com fichamento dos pacientes, identificação por leitos e a separação por doenças. Assim, o hospital passa a ser um campo documental normatizado, além de um espaço decura (Foucault, 1981).

Atualmente a organização hospitalar é uma das mais complexas, não apenas pela nobreza e amplitude da sua missão, mas, sobretudo, por apresentar uma equipe multidisciplinar com elevado grau de autonomia, para dar assistência à saúde em caráter preventivo, curativo e realibilitador a pacientes em regime de internação, onde se utiliza tecnologia de ponta de rotina e crescentemente. E se constitui, ainda, num espaço de prática de ensino-aprendizagem e produção científica (Azevedo, 1993).

De acordo com M intzberg (1995), a organização hospital ar caracteriza-se por ser uma burocracia profissional do ponto de vista estrutural, onde o setor operacional tem importância, traciona e concentra o poder na organização. 0 seu mecanismo de controle dá-se por 
padronização de habilidades realizadas por órgãos fiscalizadores externos das diversas categorias profissionais. Isto Ihe confere autonomia e independência da gerência estratégica, pois suas habilidades profissionais são definidas fora da organização em cursos profissionalizantes, ou seja, o estado da arte é um atributo das próprias corporaç̧ões que desenvolvem seu trabalho no hospital. Tal condição enfraquece a vinculação com a organização e confere dificuldades adicionais como alta resistência às mudanças.

As organizações hospitalares, públicas ou privadas, estão inseridas num ambiente complexo e singular que as condiciona a um funcionamento inadequado diante da lógica da acumulação lucrativa dos mercados. Pois, independentemente de sua natureza, ambas as condições estão subordinadas a princípios éticos e legais que normatizam o setor saúde e às políticas governamentais, que colocam os hospitais frente a uma diversidade de interesses divergentes a contemplar.

Segundo Nogueira (1994), evidenciam-se os interesses dos usuários, que demandam assistência das mais variadas formas; os interesses dos trabal hadores da saúde, que buscam seu sustento e boas condições de trabalho; os interesses dos acionistas em se tratando de hospital privado, que objetiva o lucro; os interesses da rede de fabricantes e distribuidores de insumos, das empresas seguradoras e planos de saúde, que estabelecem uma relação comercial com o hospital; e, finalmente, os interesses dos poderes formalmente constituídos na gerência hospitalar e no governo, que têm nos objetivos técnicos e no alcance de metas programáticas da política de saúde o seu foco.

No setor hospitalar observa-se uma grande resistência aos programas de qualidade em função dos médicos, que historicamente detêm 0 poder dentro destas organizações e não vêem com bons olhos a idéia de contenção de custos, nem uma avaliação do seu trabalho numa perspectiva de medir a qualidade, por se sentirem fiscalizados e terem medo de perder sua autonomia na condução clínica dos pacientes. Há também o fator financeiro, que não atrai a participação da categoria médica nestes processos. Remunerados, em sua maioria, pela produção de serviços, os médicos não desejam desperdiçar o horário de trabalho com programas dessa natureza (Berwick, 1994). Além disso, a formação médica ainda é fundamentada no modelo flexneriano, que dá ênfase à clínica em sua di- mensão biológica e no qual os aspectos sociológicos, políticos e administrativos ficam relegados ao segundo plano. Estas questões são pouco observadas nos currículos das escolas médicas, por isso há obstáculos à adesão dos médicos aos programas de qualidade, por deficiência e limitação na sua formação (O M S/OPS, 1994).

\section{Elementos para crítica construtiva aos programas de qualidade aplicados ao setor saúde}

As idéias sobre a qualidade vêm ao longo dege rações incorporando novos el ementos com a evolução das organizações e da sociedade. Entretanto, a implementação de programas de Qualidade Total tem apresentado algumas dificuldades e grandes fracassos, mesmo sendo considerado por alguns teóricos um conjunto de técnicas universais, aplicáveis a qualquer tipo de organização.

Em face desta realidade, e fazendo uma leitura deste fenômeno sob a ótica da sociologia das organizações, é possível enxergar de forma mais apropriada as razões pelas quais isto acontece.

Quatro dimensões devem ser introduzidas nesta análise. A primeira diz respeito à noção de antropofagia (Wood Jr. \& Caldas, 1999), ou seja, a simples transposição de pacotes gerenciais criados em uma realidade sociocultural específica para outra com grande possibilidade de gerar problemas de conflito entre os pressupostos básicos da técnica e os val ores centrais da sociedade em que se encontra a organização que irá adotar tal técnica. A procura de respostas prontas e soluções rápidas não permite uma análise mais detal hada no sentido da desconstrução da técnica para que se identifique seus pressu postos e os compare com os val ores básicos da cultura local, identificando, assim, possíveis adequações ao modelo que se quer implementar.

Uma segunda dimensão a ser levada em consideração é a questão da eficiência. A eficiência é sem dúvida um conceito importante. A noção de eficiência tem como pressuposto um tipo específico de racionalidade, qual seja, a racionalidade instrumental. Este tipo de racionalidade refere-se ao cálculo utilitário das conseqüências e implica, necessariamente, uma dimensão econômica que envolve a relação custo-benefício. Não se pretende aqui diminuir a 
importância dessa dimensão, mas apenas registrar que uma análise desse tipo deve estar sempre vinculada a uma análise da natureza da organização. Assim, as organizações públicas de forma geral e os hospitais, mais especificamente, devem subordinar o conceito de eficiência a critérios superiores de eficácia, efetividade e relevância, também indicadores do desempenho organizacional, incluídos nos N ove Pilares da Qualidade de Donabedian (Nogueira,1994). Uma organização pública que trata diretamente com a vida das pessoas não pode ser dirigida pela lógica da acumulação lucrativa, sob pena de pôr em cheque a própria razão de sua existência. A eficiência é uma dimensão importante da vida das organizações, mas não é a única e, em algumas circunstâncias, nem a mais importante (Penteado, 1991; Sander, 1981).

A terceira e possível explicação para os fracassos dos programas de qualidade está em grande parte relacionado com a fal ta de profundidade da análise organizacional na sua implementação. A visão da qualidade limitada aos seus aspectos instrumentais não permite enxergar com clareza a complexidade das organizações. Assim, as coalizões de poder interno, os objetivos organizacionais operativos e a cultura institucional são elementos importantes que precisam ser considerados antes da sua implementação. A adoção de programas de qualidade a partir da aplicação de manuais resumidos de avaliação de critérios de excelência, aliados a simples definição de metas mobilizadoras e elaboração de planos de melhoria, sem uma visão mais ampla e profunda do ambiente organizacional, tem conferido insucesso freqüente a inúmeras experiências, sobretudo quando se tem uma perspectiva de resultados no curto prazo ( M isoczky e Vieira, 2001; Vieira et al., 2001; Bouckaert, 1995; Rago, 1994).

Uma quarta dimensão, a percepção da qualidade e conseqüentemente seu gerenciamento, varia amplamente e implementa-se em função do grupo dominante interno na arena política da organização, que o conduz de acordo com seus interesses corporativos, negociando as divergências e conflitos de forma a permitir sua hegemonia. Os programas de qualidade, por conseguinte, tornam-se prejudicados por passar uma visão homogênea de convivência harmônica por todos os membros da organização em função de objetivos formais (Vieira \& Carvalho, 1999). Os objetivos formais podem não expressar na realidade a missão organizacional, ou seja, o que realmente ela busca. Aquilo que não está escrito e não é colocado explicitamente nos seus estatutos, mas se constitui nos seus objetivos operativos, é, muitas vezes, o que justifica o funcionamento das organizações.

Por outro lado, a satisfação dos clientes, um dos elementos fundamentais da qualidade total, apresenta alguns problemas, pois sua identificação não é precisa e as relações que se estabelecem são difusas, não se enquadrando necessariamente numa relação comercial do tipo cliente-consumidor. I sto é observado, sobretudo, em organizações prestadoras de serviços tais como os manicômios judiciais, cujo cliente não é necessariamente quem está na organização (os pacientes), mas a sociedade que se utiliza do serviço, para não conviver com elementos supostamente nocivos a ela. Esta dificuldade na identificação do cliente torna embaraçosa a avaliação de um dos critérios de excelência dos programas de qualidade, e exemplifica a impropriedade da aplicação deste princípio indistintamente para todas as organizações ( Vieira, 1997).

Para que al guém seja cliente de al guém ou de alguma organização é necessário que sejam preenchidos dois requisitos básicos. 0 primeiro diz respeito ao elemento escolha. Um cliente tem que ter o direito de escolha sobre o que lhe é oferecido. Isso chama a atenção para a falácia do conceito de cliente interno, por exemplo, pois em uma cadeia produtiva onde o trabalho de um indivíduo em uma organização depende necessariamente do trabalho de outro, esse não tem escolha a fazer. 0 segundo requisito referese ao tipo de contrato entre o indivíduo equem vai Ihe oferecer o produto ou serviço. Tal contrato deve ter fundamento comercial. Portanto, em uma organização pública ou em um hospital ou escola, só para dar alguns poucos exemplos, o conceito de cliente perde validade, uma vez que o contrato que fundamenta a relação nesses casos é do tipo "contrato social", fundamentado no direito e na cidadania, em que o fato de um serviço ou produto ser pago através de impostos não significa necessariamente que o contrato seja de natureza mercantil. Aqui novamente chama-se a atenção para o fato de que ser cliente diz respeito a um tipo específico de relação que se estabelece no âmbito do mercado, onde produtos ou serviços que constituem um negócio são trocados pela moeda corrente ou similar. No caso de um hospital, qual é o negócio? É a vida das pessoas. Parece que reduzir uma função tão nobre a uma dimensão simplista e primária envolve questões de natureza 
ética que vão muito além do imediatismo gerencial.

A aplicação de programas de qualidade total desvinculada destes pressupostos pode ser frustrante, na medida em que a sua percepção e operacionalização nas organizações estão submetidas a elementos estruturais, como a cultura e a natureza institucional, a lógica do poder interno e a definição dos objetivos operativos. Neste caso, o "sucesso" é algo relativo, em face dos agrupamentos e coal izões internas, cujos objetivos não são necessariamente os mesmos (Vieira, 1997).

Além desses elementos acrescente-se que o gerenciamento da Qualidade Total tem sua origem na engen haria e entende a organização a partir de uma abordagem mecanicista ( $M$ organ, 1996). A organização, entretanto, é um fenômeno social e as leis da engenharia, no caso analisado neste artigo, ou da biologia, metáfora também utilizada em larga escala para entender os fenômenos sociais, não podem ser aplicadas na íntegra sem um exame mais profundo de suas limitações.

No setor saúde, os programas de qualidade têm forte tendência a enfatizar a avaliação das condições dos hospitais, focalizados na infraestrutura, nos processos e resultados. Esta proposta, apesar de identificar el ementos importantes e imprescindíveis para a qualidade dos serviços, restringe-se ao diagnóstico e posicionamento das organizações com base em modelos referenciais. A identificação de problemas é apenas o primeiro passo na busca da qualidade nos serviços. Os manuais de qualidade que se limitam a isto, não fornecem elementos para melhoria necessária. A pontam os problemas, mas não apontam uma metodologia gerencial para alcançar as soluções.

Os programas de qualidade têm sua matriz na teoria sistêmica clássica que apresenta limitações em face da compreensão do jogo de forças da arena organizacional e dos conflitos de interesse típicos destas organizações. Para desenvolver programas de qualidade e processos de mudança sustentáveis com possibilidades de êxito no setor de saúde, a teoria sistêmica éinsuficiente, pela complexidade do setor e os inúmeros trade- off a considerar, sobretudo quanto à satisfação do cliente em confli to direto com a racionalidade técnica do processo de trabal ho em saúde.

$\mathrm{Na}$ atualidade, a Gestão Estratégica da qualidade propõe uma abordagem sobre as organizações que engloba uma multiplicidade de fa- tores muito difíceis de enquadrar num esque ma prescritivo simplificado. Há necessidade, portanto, de entender profundamente a organização. Para isso, é necessária uma abordagem da realidade organizacional que fundamente a ação gerencial a partir de um conjunto amplo de teorias não-circunscritas ao ambiente intraorganizacional. Neste sentido, a evolução dessas práticas no setor saúde deve enfatizar aspectos gerenciais aliados aos processos assistenciais (Quinto N eto \& Gastal, 1997), fundamentados na perspectiva do direito a saúde como um bem público, dentro do contexto da cidadania.

Estas disjunções teórico-conceituais apresentadas e os problemas metodológicos dos programas têm levado à aplicação de medicação tópica para problemas organizacionais profundos, ou a simples maquiagem de algumas inconveniências gerenciais mais si mples, como redução de filas, restringindo-se, muitas vezes, à aplicação de um pequeno conjunto de técnicas $(5 \mathrm{~S}, 5 \mathrm{~W} 2 \mathrm{H})$, incompatíveis com 0 grande número de variáveis e elementos estruturais promotores da qualidade que os programas devem a princípio manejar.

\section{Considerações finais}

A qualidade total aplicada às organizações hospitalares é al go instigante, capaz de provocar grandes discussões teóricas e um desafio a sua aplicabilidade prática. Este processo nos coloca diante de vários questionamentos, motivo pelo qual deve continuar a ser exaustivamente estudada, como forma de desenvolver modelos de gestão mais adaptados às peculiaridades e especificidades destas organizações, considerando a complexidade do seu ambiente institucional.

O bstáculos importantes podem ser encontrados nas organizações hospitalares por questões gerais relacionadas aos programas e, principalmente, em face dos elementos estruturais e das especificidades dessas organizações, já de lineadas anteriormente, que podem inviabilizar seus resultados quando aplicados de forma superficial.

A experiência do Programa Nacional de Demonstração de M elhoria da Qualidade, nos EUA, aponta para a hipótese de que a aplicação de Programas de Qualidade Total nos hospitais leva diretamente a uma maior eficiência com redução de custos, e que estes serão fundamentais para a sobrevivência de muitas organiza- 
ções de saúde, uma importante base para a competitividade destas organizações nos próximos anos (Berwick, 1994).

Entretanto, a aplicação de programas de qualidade, sob a ótica da eficiência de mercado, tem focalizado apenas aspectos instrumentais e analisa de forma reduzida o ambiente institucional das organizações, sobretudo, no setor público. Ao que parece, as medidas intraorganizacionais dos programas de qualidade têm tido baixo impacto sobre os custos do setor saúde, o que determina um alcance limitado dos programas neste sentido, quando não se observa o modelo de atenção como um todo. A superação destes problemas no sistema de saúde exige, sem dúvida, uma abordagem mais complexa em termos de política de saúde.

No Brasil ainda é cedo para tirarmos conclusões deste movimento no setor hospitalar. Uma avaliação empírica dos seus resultados faz-se necessária, mas certamente os elementos apontados neste artigo servem como referencial crítico para evitar o uso indevido do instrumental da qualidade e para não alimentarmos fal sas expectativas.

\section{Referências bibliográficas}

Azevedo CS 1993. Gerência hospitalar: a visão dos dire tores de hospitais públicos do município do Rio de Janeiro. Dissertação de mestrado. Instituto de M edicina Social, Universidade Federal do Rio Janeiro, Rio de Janeiro.

Berwick DM 1994. Sintomas do stress no sistema de serviços de saúde, pp. 1-13. In DM Berwick, AB Godfrey $\&$ J Roessner. M elhorando a qualidade dos serviços médicos, hospitalares e da saúde. M akron Books São Paulo.

Berwick DM 1994. Aplicando o gerenciamento da qualidade nos serviços de saúde, pp. 18-27. In DM Berwick, AB Godfrey \& J Roessner. M elhorando a qualidade dos serviços médicos, hospitalares e da saúde. Makron Books, São Paulo.

Berwick DM 1994. Fundamentos do gerenciamento da qualidade, pp. 30-44. In DM Berwick, AB Godfrey \& J Roessner. Melhorando a qualidade dos serviços médicos, hospitalares e da saúde. M akron Books, São Paulo.

Bouckaert G 1995. Measuring quality, pp. 20-28. In C Pollitt, G Bouckaert (eds.). Quality improvements in European public services. Sage, Londres.

Camacho JLT 1998. Qualidade total para os serviços de saúde. Nobel, São Paulo. 
Campos FE \& Albuquerque EM 1998. As especificidades contemporâneas do trabal ho no setor saúde: notas introdutórias para uma discussão, pp. 41-69. In Castro JL \& Santana JP (org.). N egociação coletiva do trabalho em saúde. OPAS/OM S-UFRN/NESC, BrasíliaNatal.

Costa N R 1996.0 Banco Mundial e a política social nos anos 90 - a agenda para reforma do setor saúde no Brasil, pp. 13-29. In NS Costa, JM Ribeiro (orgs.). Política de saúde e inovação. ENSP, Rio de Janeiro.

Foucault M 1981.0 nascimento do hospital, pp. 99-111. In Microfísica do poder. Graal, Rio de Janeiro.

Garvin DA 1992. História e evolução, pp. 3-23. In Gerenciando a qualidade: a visão estratégica e competitiva. Qualitymark, São Paulo.

Garvin DA 1992. Gestão estratégica da qualidade, pp. 2545. In Gerenciando a qualidade: a visão estratégica e competitiva. Qualitymark, São Paulo.

Garvin DA 1992. M últiplas dimensões da qualidade, pp. 59-81. In Gerenciando a qualidade: a visão estratégica e competitiva. Qualitymark, São Paulo.

Garvin DA 1992.0 movimento japonês da qualidade pp. 213-235. In Gerenciando a qualidade: a visão estratégica e competitiva. Qualitymark, São Paulo.

Garvin DA 1992. Fatores que contribuem para a qualidade japonesa, pp. 237-255. In Gerenciando a qualidade: a visão estratégica e competitiva. Qualitymark, São Paulo.

M alik AN \& Schiesari LM C 1998. Qualidade na gestão local de serviços e ações de saúde. In Série Saúde \& Cidadania. Ed. Fundação Petrópolis, São Paulo.

M edici AC 1995. Aspectos teóricos e conceituais do financiamento das políticas de saúde, pp. 23-68. In SF Piola, SM Vianna (orgs.). Economia da saúde: conceito e contribuição para a gestão da Saúde. IPEA, Brasília.

Mezomo JC 1994. Gestão da qualidade na saúde: princípios básicos. Universidade de Guarulhos, São Paulo.

Mintzberg HA 1995. Adhocracia pp. 250-277. In Criando organizações eficazes: estruturas em cinco configurações. Atlas, São Paulo.

M isoczky M C \& Vieira M M F 2001. Desempenho e qualidade no campo das organizações públicas: uma reflexão sobre significados. Revista de Administração Pública (RAP) 21(5):163-177.

M organ G 1996. Imagens da organização. Atlas, São Paulo. Nogueira LCL 1999. Gerenciando pela qualidade total na saúde. EDG, Belo Horizonte.
Nogueira RP 1994. Perspectivas da qualidade em saúde. Qualitymark, Rio de Janeiro.

OM S 1994. Contribuiç̃oes sobre a gestão da qualidade em educação médica. Série Desenvolvimento de recursos humanos n. 7. Brasília, DF.

Penteado SAT 1991. Participação na universidade: retrato em preto e branco. Editora da U NICEB, São Paulo.

Quinto Neto A \& Gastal FL, 1997. Acreditação hospitalar: proteção dos usuários dos profissionais e das instituições de saúde. Ed. Dacasa, Porto Alegre.

Quinto Neto A. 2000. A busca da qualidade nas organizações de saúde. Editora Dacasa, Porto Alegre.

Rago WV 1994. Adapting total quality management (TQM) to government: another point of view. Public Administration Review 54(1):61-64.

Sander, S 1981. Administração da educação no Brasil: evolução do conhecimento. Edições UFC-Associação Nacional de Profissionais de Administração da Educação, Fortaleza-Braślia.

Schiesari LM C 1999. Cenário da acreditação hospitalar no Brasil: evolução histórica e referências externas. Dissertação de mestrado. Faculdade de Saúde Pública Universidade de São Paulo, São Paulo, 162pp.

Vieira M M F, Calado SM R, M orais D GV, Araújo SM M, Leão J r. FPS 2001. Indicadores de qualidade na administração pública municipal: um estudo exploratório na prefeitura da cidade do Recife. Revista de Administração Contemporânea (RAC) 4(1):69-92.

Vieira M M F \& Carvalho CAP 1999. Qualidade e objetivos: implicações teóricas e metodológicas para a análise das organizações, pp. 121-147. In M M F Vieira \& LM B Oliveira (orgs.). Administração contemporânea: perspectivas estratégicas. Atlas, São Paulo.

Vieira M M F 1997. Poder, objetivos e instituições como determinantes da definição de qualidade em organizações brasileiras e escocesas. Revista de Administração Contemporânea 1(1):7-33.

Wisner JD \& Eakins SG 1997. Prêmio Baldridge, o Nobel da qualidade: 0 que há em comum entre as empresas vencedoras. HSM M anagement (1):140-146.

Wood Jr T \& Urdan F 1994. Gerenciamento da qualidade total: uma revisão crítica. Revista de Administração de Empresas 34(6):46-59.

Wood J r T \& Caldas M P 1999. Antropofagia organizacional. In Transformação e realidade organizacional: uma perspectiva brasileira. Atlas, São Paulo.

Artigo apresentado em 20/6/2001

Versão final apresentada em 10/2/2002

Aprovado em 20/2/2002 